\title{
Corporate Responsibility and Judgment Aggregation
}

Economics and Philosophy, 25 (2009) 161-77

Frank Hindriks

University of Groningen

Acknowledgments: I am grateful for comments from and discussions with Matthew Braham, David Copp, Christian List, and David Schweikard. I also benefited considerably from the session that was devoted to this paper at the LSE-Groningen Workshop 2009 on Models of Values and Opinion (Part I). Finally I would like to thank the two anonymous referees who gave me valuable feedback for improving the paper.

\begin{abstract}
Paradoxical results concerning judgment aggregation have recently been invoked to defend the thesis that a corporate agent can be morally responsible for a decision without any of its individual members bearing such responsibility. I contend that the arguments offered for this irreducibility thesis are inconclusive. They do not pay enough attention to how we evaluate individual moral responsibility, in particular not to the role that a flawed assessment of the normative reasons that bear on the issue to be decided on play in this context. I go on to propose a method for distributing corporate responsibility to individual members within the judgment aggregation framework.
\end{abstract}


When making decisions in collective settings, we often rely on majority voting. One of the features that make this decision procedure attractive, at least on the face of it, is that it does equal justice to the insights, opinions, and valuations of all concerned. However, as it turns out, when deciding on a complex matter that depends on several prior issues, a committee can end up taking a decision that hardly any, or perhaps even none of its members supports individually. Thus, a discrepancy can arise between the decision implied by the votes on the prior matters and the majority view regarding the course of action to be decided on. Philip Pettit has recently used this result, which is known as 'the Doctrinal Paradox', to argue that it is sometimes impossible to fully distribute the responsibility of a corporate agent to the individual members of that agent. As this claim implies that corporate responsibility is irreducible, I shall call it 'the Irreducible Corporate Responsibility thesis'. The thesis is, of course, familiar from philosophers such as Peter French (1984: 16). What is new is that a formal model of collective decision-making, the judgment aggregation framework, is used to develop arguments in its favor.

Another paradoxical finding concerning judgment aggregation is the Discursive Dilemma, which consists in the fact that inconsistencies can arise when committee members cast votes both on the premises and the conclusion of an argument or decision problem. David Copp (2007) considers a case in which inconsistent views formed in this way are communicated to someone who is adversely affected by the decision the corporate agent makes on the basis of these views. Copp goes on to argue that the adversely affected individual has a legitimate ground for complaint against the corporate agent, even though none of its individual members can be blamed. His argument is based on the fact that the individuals involved in the decision followed a well-established policy of the corporate agent at issue.

I shall argue that both Pettit's and Copp's arguments in favor of the Irreducible Corporate Responsibility thesis are flawed. In order to unravel their arguments I start by investigating some of the subtleties involved in normative assessments of actions performed by individual agents. I argue that blameworthiness can often be traced back to a flawed evaluation of the normative reasons that bear on the decision made. Appreciating how such assessments can be flawed and what role such flaws play in our assessment of decisions of individuals will turn out to be of crucial importance for assessing the contributions individuals make to the evaluation of such reasons by corporate agents facing similar decisions. The role normative reasons play in assessments of decisions in general easily gets overlooked in the case of corporate agents when the only thing the individuals involved in the collective 
decision-making process are asked to do is to cast a vote on logically independent component issues. Making that role explicit serves to cast doubt on these arguments for the Irreducible Corporate Responsibility thesis. Furthermore, it motivates my positive proposal, which is that corporate responsibility be distributed according to the contribution individuals make towards the corporate agent's assessment of the pertinent normative reasons.

\section{The Doctrinal Paradox and the Discursive Dilemma}

The famous example of the kind of discrepancy that lies at the source of the arguments mentioned concerns a multi-member court that has to decide whether a defendant is liable under a charge of breach of contract (Kornhauser and Sager 1993). In order to establish whether the defendant is indeed liable the court has to consider the following two propositions:

$p$ : A valid contract was in place.

$q$ : The defendant's behavior was such as to breach it.

The conclusion that has to be accepted or rejected is proposition $r$ :

$r$ : The defendant is liable.

According to legal doctrine, the defendant is liable exactly if both propositions $p$ and $q$ are true. Thus, propositions $p$ and $q$ can be regarded as the premises of an argument that has $r$ as its conclusion.

\section{INSERT TABLE 1 HERE}

Suppose that the beliefs of the three judges involved in a case like this are as presented in table 1. Judge A regards the contract as valid, but does not believe the defendant violated its conditions. Judge B holds that the contract was invalid, but that, had it been valid, the defendant would have violated it. Only judge $\mathrm{C}$ believes both that a valid contract was in place and that the defendant's behavior was such as to breach it. In this example, to which I shall refer as 'Liability', two out of three believe the defendant is not liable. If votes were taken on the conclusion only, the defendant would not be convicted. However, the defendant 
would be found liable, if votes were taken on the two prior issues instead. After all, each of the premises of the argument is accepted by a majority of the judges. The former procedure is known as the conclusion-based procedure, the latter as the premise-based procedure. The possible discrepancy between these two decision procedures is known as 'the Doctrinal Paradox'.

The Doctrinal Paradox reveals that a corporate agent can accept a certain conclusion or take a particular decision by relying on majority voting even if that decision or conclusion would not be accepted if it were subjected to majority voting directly. In such a situation, a majority of the committee members disagree with the conclusion or decision. For ease of reference, I shall call cases for which this holds 'Disagreement Cases'. A special kind of Disagreement Case is one in which the conclusion that is accepted by the corporate agent is supported by none of its members.

Liability can also be used to illustrate another problem that can arise in the context of collective decision-making, which has become known as 'the Discursive Dilemma'. Suppose that the three judges were to vote both on each of the two premises and on the conclusion, and that the majority votes on each of the three propositions were to constitute the court's view on those propositions. Given the distribution of the votes presented in table 1 this would result in the corporate agent having formed an inconsistent set of judgments. Roughly speaking the Discursive Dilemma consists in the fact that no attractive voting procedure exists that rules out the possibility that a corporate agent relying on it ends up forming inconsistent judgments.

These two paradoxes are studied systematically in the literature on judgment aggregation. Key notions in this literature are that of an agenda, that of a connection rule, and that of an aggregation rule. An agenda consists of those propositions on which judgments are to be made. A connection rule is a rule that connects the premises to the conclusion. In Liability, the connection rule is conjunctive, which means that the conclusion is accepted exactly if all of the premises are accepted. Connection rules can invoke other logical relations as well, including for instance disjunction or material implication. Often the connection rule is an exogenous constraint. In Liability it is a legal doctrine. In one of the cases I consider below the connection rule is part of the agenda. Procedures, such as majority voting, that map profiles of individual judgment sets to a collective judgment set are aggregation rules. It turns 
out that virtually all intuitively attractive aggregation rules are susceptible to inconsistencies at the collective level. ${ }^{1}$

As is discussed in section 4, David Copp uses the Discursive Dilemma in order to develop an argument in favor of the Irreducible Corporate Responsibility (ICR) thesis. In the remainder of this section I shall explicate how Pettit invokes the Doctrinal Paradox for the same purpose. Pettit considers a participatory organization in which the members have to decide whether or not to introduce some kind of safety measure. Doing so requires foregoing a pay rise. This in turn depends on three (logically) prior issues $p, q$, and $r$ :

$p$ : There is a serious danger of electrocution.

$q$ : The proposed safety measure is likely to be effective against this danger.

$r$ : The pay sacrifice involves a loss that is bearable.

The decision or conclusion that is to be accepted or rejected is $s$ :

$s$ : The pay sacrifice should be made.

This decision problem, to which I shall refer as 'Employee Safety', is framed in such a way that the pay sacrifice is to be accepted exactly if all of the three premises are accepted. In other words, the connection rule is as follows: $(p \wedge q \wedge r) \rightarrow s$. The Doctrinal Paradox reveals that whether or not the pay sacrifice is accepted depends not only on the distribution of the votes, but also on whether the individuals involved vote on the premises or on the conclusion. The way the individual members judge the relevant issues is depicted in table 2 (Pettit assumes that people vote as they judge; 2007: 198). Just as Liability, Employee Safety is a Disagreement Case. None of the individuals favors the pay sacrifice. However, if votes are cast on the premises rather than on the conclusion - i.e. if a premise-based rather than a conclusion-based procedure is used - it will be accepted nevertheless. After all, each of the premises is supported by a majority of the voters.

INSERT TABLE 2 HERE

\footnotetext{
${ }^{1}$ See List (2008) for an introduction to the literature on judgment aggregation, and a more precise formulation of the paradoxes (including a characterization of what I call intuitively attractive aggregation rules').
} 
Imagine that the pay sacrifice at issue in Employee Safety is in fact unjust. Each of the individuals who cast the votes might think she bears no responsibility. After all, each of them opposes the pay sacrifice. Pettit argues that this thought provides support for the claim that a corporate agent might be responsible without any of its members being responsible, the ICR thesis presented earlier. He makes the point as follows:

But suppose now that some external parties have a complaint against the group, say, the spouses of the less-well-off workers, who think the pay sacrifice unfair. Whom, if anyone, can they hold responsible for the line taken? Whom can they remonstrate with? Not the individuals in their personal right, since each can point out, the chair included, that he or she was actually against the pay sacrifice and that they were not in a position, as well they may not have been, to see the likely effect of the procedure followed. The spouses in this example can only blame the corporate group as a whole. (Pettit 2007: 198; emphasis added; see also 2001: 122)

The key idea that Pettit defends in this passage is that an individual cannot be blamed for a decision made by the corporate agent of which she is a member if she disagrees with it. In other words, Pettit regards the following condition, to which I shall refer as 'condition E', as an excuse condition:

[E] An individual member of an organization cannot be blamed for a decision made by that organization if $s /$ he disagrees with it.

According to condition E, disagreement as such is an exculpating factor.

I shall argue that this claim is too strong, and that disagreement is a legitimate excuse only if one disagrees with a decision for the right reasons. The thing to see is that decisions for which one can be held morally responsible involve normative reasons, i.e. moral considerations that should be counted in favor or against the relevant issue. Someone's assessment of the normative reasons that bear on her action is crucial for determining whether, and if so to what extent, someone is to be blamed. In order to develop my case, I 
start in section 2 by considering how normative reasons enter into the ascription of moral responsibility. $^{2}$

\section{Moral Responsibility and Faulty Self-Governance}

Moral responsibility can be ascribed only to moral agents, agents who can recognize normative considerations, and who can guide their behavior by the light of an appreciation of their force. The mere fact that someone caused harm does not entail that she is blameworthy. After all, the harm might be due to an accident. In addition to this, the control that the agent exerted over her action - which Pettit $(2001,2007)$ calls 'reason-sensitive control' - must have been flawed in one way or another. Jay Wallace has made this point in terms of the claim that one can be blamed legitimately only if one has 'a culpable quality of the will' (1994: 151). This is the case if the choice one has made that is expressed by the action one performs does not reflect the normative reasons one accepts. In other words, the reasons that motivated the action are in conflict with the normative reasons expressed in one's accepted moral principles (ibid., chapter 5).

Thomas Scanlon makes essentially the same point in terms of his notion of faulty selfgovernance. Consider the following passage:

If an action is blameworthy, then the agent has either failed to take account of or knowingly acted contrary to a reason that should [...] have counted against his action. So, in addition to whatever loss this action may have caused, the agent's mode of selfgovernance has ignored or flouted requirements flowing from another person's standing as someone to whom justification is owed. This is what makes the action wrong rather than merely harmful [...]. (1998: 271)

According to Scanlon, then, blameworthiness requires faulty self-governance. He distinguishes between 'two different kinds of fault in the reasons a person recognizes and is moved by' (ibid.: 268): one can fail to note normative considerations that bear on an action, and one can ignore a conclusive reason against it. Faulty self-governance of one of these

\footnotetext{
${ }^{2}$ See Dancy (2000), Scanlon (1998), and Smith (1994) for the distinction between motivating or operative reasons on the one hand and normative reasons on the other.
} 
kinds is what makes a harmful action wrong. Note that often several considerations are relevant to a particular decision, and that someone's self-governance can be flawed because she weighs these considerations in the wrong way rather than just - as the passage could be taken to suggest - because one fails to take one of them into account.

Let me illustrate the role of faulty self-governance in the assignment of moral responsibility. Suppose you have made plans to meet up with a friend who is going through a rough period, perhaps because he recently got divorced. When the time approaches, you turn out to be very busy with things at work. Because of this, you call your friend to say you do not have time to meet. Later you learn your friend really counted on you and was very disappointed. With hindsight you conclude you should have attached more significance to the emotional distress your friend was experiencing and the role you could have played in relieving it. This is a case of faulty self-governance. Your flawed assessment of the normative reasons involved provides legitimate grounds for blame.

As will prove to be important below, a failure to act on the right reasons can also be the basis for withholding praise. Suppose that you do meet up with your friend, but only because you are afraid that, if you do not, he will complain about you and damage your reputation as a considerate person. Even though what you do might be right, you do it for the wrong reasons. Presumably you do not deserve any praise in this case. This is particularly clear if your fear is in fact unjustified. Your friend would never complain about you to other people. Had you known this, you would not have met up with your friend. Hence, you would have made the wrong decision.

Because of the role that a correct assessment of reasons plays in it, I shall refer to the conception of moral responsibility discussed here as 'the Right Reasons Conception of Moral Responsibility'. In addition to those of Wallace and Scanlon it encompasses Susan Wolf's (1990) conception of moral responsibility. She recognizes the point I just made that '[a]n action is praiseworthy only if it is done for the right reasons' (ibid.: 80). More generally, she argues that moral responsibility requires 'the freedom and power to do the right thing for the right reasons' (ibid.: 77). On her view it only makes sense to blame someone for doing something wrong if he is able to do the right thing for the right reasons. Someone who is blameworthy must have made one of two mistakes: either the way in which he assessed the the reasons bearing on his action is flawed, or he failed to act on his (possibly flawless) 
assessment (ibid., 87-89). The former is exactly what Scanlon has in mind when he talks about faulty self-governance. ${ }^{3}$

Note that an agent can be blameworthy because he does not carefully consider the available information, and, as a consequence, is not aware of the fact that the action he ends up performing is harmful. In such cases, ignorance is due to faulty self-governance. ${ }^{4}$ Ignorance, however, can also function as an exculpating factor. This will be the case if the relevant agent could not reasonably have been expected to know that his action would cause harm. In such cases one's causing harm is not due to a flawed appreciation of the normative issues involved. These are cases of blameless harm. In my critique of Pettit's argument for the ICR thesis, I shall assume that the agents have carefully considered the available information. ${ }^{5}$

\section{Disagreement and the Distribution of Corporate Responsibility}

In section 1 we saw that Pettit regards disagreement with the corporate agent's decision on the part of an individual as an exculpating factor (see condition E). This opens up the possibility of a corporate agent being blameworthy without any of its members being blameworthy (the ICR thesis). In section 2 I have argued that blame can often be traced to a flawed assessment of the normative reasons at issue. The thing to see now is that the mere fact that one disagrees with a faulty decision does not imply that one has an adequate appreciation of the relevant

\footnotetext{
${ }^{3}$ Given that the judgment aggregation framework is cast in terms of propositions that are either true or false one could get the impression that the Right Reasons Conception of Moral Responsibility as employed in this context is committed to moral realism. This, however, is not the case. A positive (negative) judgment about a premise that has normative content need not be taken to involve more than acceptance of the consideration involved in that premise as bearing on the decision at hand according to the way in which one judges. No commitment to normative reasons being true or false is required. Note finally that some forms of moral antirealism, such as Blackburn's quasi-realism, allow for moral truths.

${ }^{4}$ See Nottelmann (2007) for a useful discussion of conditions under which someone can be blameworthy for holding a particular factual belief.

${ }^{5}$ Rosen (2003) has argued that in some cases an agent is not in a position to determine what is the morally correct decision. As the arguments he provides apply equally to individual and collective agents, I abstract from this issue as well.
} 
moral issues. This suggests that the excusing condition Pettit has formulated is too broad. The alternative for condition $\mathrm{E}$ that $\mathrm{I}$ propose is condition $\mathrm{E}^{*}$ :

[E*] An individual's disagreement with the decision the organization of which $s / h e$ is a member affects the extent to which s/he can be blamed for that decision only if $\mathrm{s} / \mathrm{he}$ disagrees with it for the right reasons.

According to condition $\mathrm{E}^{*}$, disagreement is an exculpating factor only if it is based on an appropriate assessment of the relevant normative reasons. Given this more narrowly circumscribed excusing condition, Disagreement Cases no longer pose a problem for the reduction of corporate responsibility, or so I shall argue.

[E*] fits with the Right Reasons Conception of Moral Responsibility discussed in section 2, which Pettit accepts. In this section I provide further support for [E*] by means of an extended example. I start below by considering how we would evaluate the responsibility of individuals in the case at hand depending on their appreciation of the issues that bear on the decision. Subsequently I consider the case in which a corporate agent is made up of individuals who judge in the various ways discussed earlier. Together their judgments form a Disagreement Case. We shall see that, in spite of this being a Disagreement Case, moral responsibility can be assigned to particular individuals in a relatively straightforward way. In section 3.2 I apply the method for distributing responsibility presented in section 3.1 to Employee Safety.

\subsection{Preemptive War}

Consider a benevolent dictator $\mathrm{D}$ of an imaginary country $\mathrm{X}$ who faces the choice whether or not to go to war with a neighboring country $\mathrm{Y}$. The government of country $\mathrm{Y}$ is a reprehensible one. It oppresses its subjects and it aims to expand its territory at the expense of its surrounding countries. Some time ago it did not have sufficient means for waging a war that had any chance of success. The evidence suggests, however, that it has recently acquired weapons of mass destruction (hereafter WMD). Given all that is known about country $\mathrm{Y}$ and its government, it is reasonable to expect that those weapons will be employed in the near future if they have indeed been acquired. This will create a large number of casualties among the inhabitants of country X. Apart from this clearly weighty issue there is no reason to attack country $\mathrm{Y}$. In addition to assessing the evidence in favor of the presence of WMD, D has to 
determine whether country $\mathrm{X}$ has the military capacity to attack country $\mathrm{Y}$ and disarm it. Furthermore, he has to make up his mind whether it is just to wage a preemptive war.

The decision problem faced by $\mathrm{D}$ can be represented in terms of three premises $p, q$, and $r$, and a conclusion $s$ :
$p$ : Country Y has WMD.
$q$ : Country $\mathrm{X}$ has the military capacity to remove the WMD from country $\mathrm{Y}$.
$r$ : If country $\mathrm{Y}$ has $\mathrm{WMD}$ and if country $\mathrm{X}$ has the military capacity to remove them from country $\mathrm{Y}$, country $\mathrm{X}$ should wage a war against country $\mathrm{Y}$.
$s$ : Country X should wage a war against country Y.

The third premise, $r$, is the connection rule. Its formal structure is as follows: $(p \wedge q) \rightarrow s$. In contrast to the previous examples, it is not exogenous but part of the agenda. Premise $p$ clearly concerns a purely factual matter, and I shall assume that this holds for premise $q$ as well. In addition to this, I shall assume that both premises $p$ and $q$ are true. Premise $r$ concerns a normative issue. It should only be accepted if preemptive wars in situations such as this one are just. ${ }^{6}$

Now suppose that D judges all three premises to be true. As a consequence, he accepts the conclusion. Whether or not this decision is correct is a difficult issue on which opinions diverge. Suppose, however, that, even though country Y does possess WMD and country X does have the military power to disarm country $\mathrm{Y}$, waging a preemptive war is in fact unjust in the case at hand because a diplomatic solution might be available. ${ }^{7}$ Then country $\mathrm{X}$ will have inflicted serious harm on country $\mathrm{Y}$ without appropriate justification. The question arises as to whether anyone deserves to be blamed. D is the only available candidate, or so we can safely presume. There is no exculpating condition, so given what was said about responsibility and blameworthiness in the previous section dictator D does indeed deserve blame. Given the supposition made, this is due to his evaluation of the normative reasons pro and con premise $r$. This makes the case, to put the point in Scanlon's terms, one of faulty self-

\footnotetext{
${ }^{6}$ See Dietrich and List (2007a) for another example that involves WMD.

${ }^{7}$ According to just war theory, six conditions have to be met in order for a war to be just (Orend 2005). These concern just cause, right intention, proper authority and public declaration, probability of success, proportionality, and last resort. The condition of last resort fails to be met if a diplomatic solution is available.
} 
governance. Just as we saw in the friend in distress example discussed in section 2, D is blameworthy because he fails to appreciate the true force of the relevant normative reasons.

Before turning to a collective setting in which decisions are made by means of judgment aggregation, we should know how to assess a dictator who decides against a preemptive war. Such a dictator will not be blamed for anything. After all, country Y is not harmed, and the decision not to wage war was just (by hypothesis, the risk of being harmed to which country $\mathrm{X}$ is exposed as a consequence is justified by the probability that the problem can be solved by diplomatic means). This does not mean, however, that there cannot be any morally relevant differences between dictators who would make this decision. As we saw in the previous section, how their decisions should be evaluated depends on the reason(s) they had for making it.

Consider dictators A, B, and C. Each of them accepts two of the three premises. Furthermore, each rejects a different premise. A decides against a preemptive war because he comes to the conclusion that country Y does not have any WMD, B because he judges that the military power of country $\mathrm{X}$ is insufficient, and $\mathrm{C}$ believes preemptive wars of the kind at issue are unjust. Both $\mathrm{A}$ and $\mathrm{B}$ accept the normative premise $r$. They do the right thing, but only because they are mistaken about a (non-normative) matter of fact. Only $\mathrm{C}$ makes the right decision for the right reasons. Both $\mathrm{A}$ and $\mathrm{B}$ make factual mistakes. In a way analogous to the second version of the friend in distress example - the one in which you end up meeting your friend, but only do so because you mistakenly believe he would damage your reputation otherwise - they make the right decision not for the right reasons but only because of a false belief. If praise were in order for making the right decision in this case, only $\mathrm{C}$ would deserve such praise, as only he makes it for the right reasons.

\section{INSERT TABLE 3 HERE}

If, instead of being dictators, $\mathrm{A}, \mathrm{B}$, and $\mathrm{C}$ were the only three members of the government of country $\mathrm{X}$ and together they had to determine whether or not to wage a preemptive war, their combined judgments would constitute a Disagreement Case, as can be gathered from table 3. None of the members of the government supports a preemptive war. Nevertheless, the government they constitute decides in favor of it due to its reliance on the premise-based procedure. If we were to go by Pettit's assessment of such cases, only the government is responsible, and none of its individual members are. Just as Pettit did regarding Employee Safety, we can ask: Who, if anyone, can the citizens of country Y hold responsible 
and blame for the decision taken? Not the individuals in their personal right, since each can point out that he actually opposed the preemptive war. In contrast to what this line of reasoning suggests, however, it is possible to distribute responsibility to some of the individuals involved. Our assessment of A, B, and C in their role of dictator reveals how. The government of country $\mathrm{X}$ reasons just like dictator D. Its evaluation of the normative issues involved is flawed because it accepts the third premise $r$. Hence, it is guilty of faulty selfgovernance. Now, the government judges a preemptive war to be just because a majority of its members consisting of $\mathrm{A}$ and $\mathrm{B}$ judges it to be just. So A and B are the individuals who can be blamed.

Implicit in my treatment of this case is an algorithm for distributing responsibility in Disagreement Cases, which consists of two steps. When an action based on the decision made causes harm, the first step is to determine whether the case at hand is one of faulty selfgovernance. If not, no one is to be blamed. If it is, the thing to do is to make explicit where the corporate went wrong in its reasoning, i.e. to identify those premises about which the collective has formed a faulty judgment. The second step is to identify those individuals who contributed to the corporate agent's faulty assessment of the normative issues involved, the ones who - just as A and B in the case discussed in this section - are guilty of faulty selfgovernance. They are the ones who are candidates for blame.

\subsection{Employee Safety}

The algorithm for distributing corporate responsibility to individual members proposed in the previous section can be applied to Employee Safety in a relatively straightforward way. The first step is to determine whether it is a case of faulty self-governance. In order to do this, we need to determine which, if any, of its premises are normative. As described by Pettit, the questions involved are these: 'first, whether there is a serious danger of electrocution, by some agreed benchmark; second, whether the safety measure that a pay sacrifice would buy is likely to be effective against the purported danger, again by an agreed benchmark; and third, whether the pay sacrifice involves an intuitively bearable loss for individual members.' (2007, 197) It is not a completely straightforward matter to determine which of these premises are normative. Perhaps they all are. The third premise basically bears its normative character on its sleeve. The question whether the pay sacrifice is bearable comes down to the question whether it is fair for the employees to forego a pay rise. This is a matter of justice. Determining whether the pay sacrifice is bearable requires weighing the pros and cons. 
Among the pros is the possibility of saving someone's life (or preventing her death). The cons include the lack of an increase in standards of living (which might be long due).

The danger of electrocution and the effectiveness of the safety measure are to be judged relative to an agreed upon benchmark. Because of this, it is at least somewhat plausible to regard the first two premises as concerning matters of objective fact. To be sure, whether the benchmarks are adequate might be a normative matter. Suppose, however, that the employees themselves have set the benchmarks appropriately, or that the benchmarks have been determined by some government agency that is generally presumed to be highly competent in setting the requisite safety standards. Then we can treat the first two premises as if they concern matters of fact only. This in turn implies that Employee Safety is structurally identical to Preemptive War (see tables 2 and 3), and that the only premise involving normative issues is the third one, premise $r$. The judgment the corporate agent forms on this premise is flawed, which implies that the way in which the corporate agent governed itself was faulty. The second step consists of identifying the individuals who have contributed to the faulty self-governance of the corporate agent. The fact that the participatory organization accepts $r$ is due to agents $\mathrm{A}$ and B. So, the responsibility of the corporate agent can be distributed to these two individual members. ${ }^{8}$

The remaining question is whether the algorithm presented above provides the means for distributing responsibility to individuals in every case. After all, Pettit needs only one case in which someone is blameworthy but no individual is in order to establish the ICR thesis. Although I have no proof, there is reason to be optimistic about this. The Doctrinal Paradox arises only with respect to multiple propositions. The Right Reasons Conception of Responsibility facilitates a move from a moral evaluation of the decision or conclusion to a moral evaluation of judgments about particular premises. As a consequence, the fact that the Doctrinal Paradox can arise regarding multiple propositions ceases to be relevant for the distribution of blame.

\section{Inconsistency and Legitimate Expectations}

\footnotetext{
${ }^{8}$ The argument does not depend on this particular way of evaluating the moral features of the case at issue. If any of the other two premises involves a normative issue as well and the corporate agent should not have accepted it, the individuals who voted in its favor can be blamed as well.
} 
Just as Pettit, Copp (2007) employs the judgment aggregation framework in order to defend the ICR thesis. Whereas Pettit focuses on the fact that relying on the premise-based procedure puts a corporate agent at risk of making a decision that is supported by a minority of its members at best, Copp zooms in on the inconsistency that can arise in the judgments of an organization if votes are cast both on the premises of a decision problem and its conclusion. In other words, he bases his argument on the Discursive Dilemma rather than on the Doctrinal Paradox. More precisely, Copp is concerned with the ramifications of an inconsistency in a corporate agent's views becoming public.

The example Copp uses concerns a tenure candidate, Mr. Borderline, whose qualifications in research, teaching, and service are assessed by a three-member committee. ${ }^{9}$ The university's standard for tenure says that excellence in all three areas is necessary and sufficient for tenure. The members are required to vote both on the premises and the conclusion. As it happens, each of the three members believes Mr. Borderline has failed to achieve the standard of excellence in a different area. Hence, the votes in Tenure Committee are distributed just as in Employee Safety (see table 2). The upshot is that each committee member individually votes against awarding tenure to Borderline. The university's policy stipulates that the committee members first vote on the candidate's qualifications in each of the three areas. It also instructs them to cast their votes on the issue of tenure directly. The majority on a given proposition constitutes the university's view on the relevant issue. Thus, the university's view on the conclusion implies that tenure should be denied. The university's views on the premises, however, imply that Mr. Borderline should receive tenure.

Copp also stipulates that the judgments regarding all the propositions be communicated to the candidate. The committee is required to inform candidates of its decisions as they are taken, but without revealing how the members voted' (ibid., 379). The policy also states that the decisions of the university are final. On the basis of the votes on the conclusion the university denies tenure to Borderline even though it judged him to have achieved excellence in all three areas. Thus, the university violates its own standard for tenure. Copp concludes that the decision is unfair. The university frustrates legitimate expectations on the part of Mr. Borderline, who had reason to expect the university to abide by its own standard. Given that he received the decisions according to which he had achieved excellence in each of the three areas, he had reason to expect to be awarded tenure. Hence, the

\footnotetext{
${ }^{9}$ See Bovens and Rabinowicz (2006) for an earlier example in the literature on judgment aggregation that concerns tenure.
} 
denial of tenure is a harm for which the university is to be blamed. At the same time, Copp argues, none of the committee members is blameworthy: 'They acted reasonably and in accord with their duties as members of the committee and their individual votes were fair and accurately reflected their judgments about Borderline's deserts.' (Ibid.: 380)

Copp denies that some individual within the university might be blameworthy for the university having faulty procedures. He stipulates that 'the university is an ancient one, that it has had these rules for two hundred years, and that it has never before faced a problem of the kind that arose in Borderline's case' (ibid.: 380). Furthermore, he adds that the case arose long before voting paradoxes became widely known. These considerations all suggest that there was no way of knowing that the university's procedures were faulty. The thing to note is that this suggests that the case is one of non-culpable ignorance. If it is, it is a case of faultless harm. There simply was no fault in the self-governance either on the part of the university as such, or on the part of any of its individual members (the university may, of course, have a duty to remedy the harm caused).

One might object to this and argue that something had to be done as soon as it became clear that the university's decisions would become inconsistent. This became apparent once the votes on the conclusion had been counted. The responsibility for taking action at that stage, however, cannot lie with anyone else than with the committee members. At that stage, they are the only ones who know about the discrepancy. They are confronted with the fact that the policies their university employs are incoherent. Because of the votes on the conclusion, the university has decided against tenure. However, the votes on the premises entail that tenure should be awarded, as the university's procedures require exactly that the candidate be judged excellent in all three areas. And given that the majority does, the university judges in this way.

This means that the issue has become one of how to handle an inconsistency in the university's decisions. The members or the chair of the committee presumably have a duty to alert the board of the university of the impendent problem. Someone with the discretion to overrule university decisions has to overrule one of the decisions before the discrepancy becomes public, or - if this is no longer possible - remedy the unfair treatment of the candidate after the fact. Blame is justified only if neither of these two options is pursued. And it is possible to distribute the blame to one or more individuals, perhaps to the chair of the 
committee if she refrains from alerting the board of the university of the inconsistency, or to the chair of the board if she fails to prevent or remedy the unfair decision. ${ }^{10}$

Copp could respond to this criticism by appealing to other ancient and time-honored rulings that foreclose these escape avenues. It seems, however, that criticisms similar to the ones proposed above apply to this response as well. If the key issue is that there has never been a reason to doubt the adequacy of these rules and that this provides sufficient reason for following them, the case is one of faultless harm. Perhaps this criticism is inadequate, as it would imply that no one is to blame even though one or several members of the university foresee that harm will be caused. If this is the case, however, it seems the blame can be distributed to those individuals. After all, they are the only ones who are in a position to prevent the harm.

Copp's argument is based on the supposition that the fact that respectable rules are in place exculpates individual members even though it does not exculpate the organization. This supposition seems false in cases in which the harm caused is foreseen. And the only reason why the issue of fairness surfaces in Tenure Committee is that the inconsistency is out in the open. Just as orders should sometimes be disobeyed, even when made by a respectable official, sometimes rules should be broken. The rules do not exculpate the individuals involved in cases like this (or, if they do, there is no reason to believe they do not exculpate the organization too). Thus, an appreciation of all of the normative reasons that bear on the issue at hand resolves Copp's conundrum. Just as before, an in depth investigation of responsibility and blame at the individual level resolves the issue and facilitates the distribution of responsibility to individuals.

\section{Conclusion}

The upshot is that in order to appreciate the relevance of the paradoxes concerning judgment aggregation to corporate responsibility one first needs to disentangle the normative issues

\footnotetext{
${ }^{10}$ Copp (2007: 381) argues that 'the university had an all-in obligation not to deny tenure to Borderline' even though none of the committee members had an all-in obligation to vote in favor of tenure. What is more, they were permitted to vote against tenure. I do not dispute any of this. Instead, I have in effect argued that the members had a duty to try to prevent that the university would act according to their votes, or to attempt to get the university to remedy the untoward outcome.
} 
involved in the decision problem independently from the collective context. More information is needed than that which is provided by a matrix that contains the views of the individuals involved on the premises and the conclusion. And merely adding a normative assessment of the conclusion, as Pettit in effect proposes, will not do. The first question to consider is how one would evaluate an individual who had decided in the way the corporate agent decided. This will reveal whether the case might be one of faultless harm, and facilitates the identification of the fault in self-governance in case someone does deserve blame. The second step to be taken consists of tracing the fault in self-governance to particular individuals.

At a more general level the message is that, when using the judgment aggregation framework in relation to practical issues such as moral responsibility, one needs to carefully consider which information has to be added in order to be in the position to draw substantial conclusions. In addition to whether a decision as such might be morally problematic, one needs to know what normative reasons were involved in the decision problem. This idea extends to decisions made on the basis of rules or policies, the case on which Copp focuses. The arguments that Pettit and Copp have put forward can be defused by first determining what the correct or morally appropriate way is of reaching the relevant decision, to the extent there is one. This can subsequently be used as a point of departure for distributing responsibility to the individuals involved in the collective decision-making process. Doing this carefully reveals that their arguments do not support the thesis that a corporate agent can be morally responsible without any of its individual members bearing such responsibility.

\section{References}

Bovens, L. and W. Rabinowicz 2006. Democratic Answers to Complex Questions - An Epistemic Perspective. Synthese 150: 131-53.

Copp, D. 2007. The Collective Moral Autonomy Thesis. Journal of Social Philosophy 38: 369-88.

Dancy, J. 2000. Practical Reality. Oxford: Clarendon Press.

Dietrich, F. and C. List 2007a. Judgment Aggregation by Quota Rules. Journal of Theoretical Politics 19: 391-424.

Dietrich, F. and C. List 2007b. Strategy-Proof Judgment Aggregation. Economics and Philosophy 23: 269-300. 
French, P. 1984. Collective and Corporate Responsibility. New York: Columbia University Press.

Kornhauser. L.A. and L.G. Sager 1993. The One and the Many: Adjudication in Collegial Courts. California Law Review 81: 1-59.

List, C. 2006. The Discursive Dilemma and Public Reason. Ethics 116: 362-402.

List, C. 2009, forthcoming. Judgment Aggregation: A Short Introduction. In Handbook of the Philosophy of Economics, ed. U. Mäki. Amsterdam, Elsevier.

Nottelmann, N. 2007. Blameworthy Belief. A Study in Epistemic Deontologism. Dordrecht: Springer.

Orend, B. 2005. War. Stanford Encyclopedia of Philosophy (Winter 2005 Edition), ed. E.N. Zalta. URL $=<$ http://plato.stanford.edu/archives/win2005/entries/war/>.

Pettit, P. 2001. A Theory of Freedom. From the Psychology to the Politics of Agency. Oxford: Oxford University Press.

Pettit, P. 2003. Groups with Minds of Their Own. In Socializing Metaphysics. The Nature of Social Reality, ed. F.F. Schmitt, 167-94. Lanham: Rowman \& Littlefield.

Pettit, P. 2007. Responsibility Incorporated. Ethics 117: 171-201.

Rosen, G. 2003. Culpability and Ignorance. Proceedings of the Aristotelian Society 103: 6184.

Scanlon, T.M. 1998. What We Owe to Each Other. Cambridge (MA): Harvard University Press.

Smith, M. 1994. The Moral Problem. Oxford: Blackwell.

Wallace, R.J. 1994. Responsibility and the Moral Sentiments. Cambridge (MA): Harvard University Press.

Wolf, S. 1990. Freedom Within Reason. Oxford: Oxford University Press. 